\title{
Mandates and the Incentive for Environmental Innovation
}

\author{
Matthew S. Clancy and GianCarlo Moschini
}

Working Paper 15-WP 557

June 2015

\author{
Center for Agricultural and Rural Development \\ lowa State University \\ Ames, lowa 50011-1070 \\ www.card.iastate.edu
}

Matthew S. Clancy is a Ph.D. candidate, Department of Economics, lowa State University, Ames, IA 50011. Email: mclancy@iastate.edu

GianCarlo Moschini is Professor and Pioneer Chair in Science and Technology Policy, Department of Economics and Center for Agricultural and Rural Development, lowa State University, Ames, IA 50011, USA. Email: moschini@iastate.edu.

This publication is available online on the CARD website: www.card.iastate.edu. Permission is granted to reproduce this information with appropriate attribution to the author and the Center for Agricultural and Rural Development, lowa State University, Ames, lowa 50011-1070.

Iowa State University does not discriminate on the basis of race, color, age, ethnicity, religion, national origin, pregnancy, sexual orientation, gender identity, genetic information, sex, marital status, disability, or status as a U.S. veteran. Inquiries can be directed to the Interim Assistant Director of Equal Opportunity and Compliance, 3280 Beardshear Hall, (515) 294-7612. 


\title{
Mandates and the Incentive for Environmental Innovation
}

\author{
Matthew S. Clancy and GianCarlo Moschini*
}

\begin{abstract}
Mandates are policy tools that are becoming increasingly popular to promote renewable energy use. In addition to mitigating the pollution externality of conventional energy, mandates have the potential to promote R\&D investments in renewable energy technology. But how well do mandates perform as innovation incentives? To address this question, we develop a partial equilibrium model with endogenous innovation to examine the R\&D incentives induced by a mandate, and compare this policy to two benchmark situations: laissez-faire and a carbon tax. Innovation is stochastic and the model permits an endogenous number of multiple innovators. We find that mandates can improve upon laissez faire, and that the prospect of innovation is essential for their desirability. However, mandates suffer from several limitations. A mandate creates relatively strong incentives for investment in $\mathrm{R} \& \mathrm{D}$ in low-quality innovations, but relatively weak incentives to invest in high-quality innovations, so that the dispersion of realized innovation quality is comparatively low. Moreover, a mandate achieves lower welfare than a carbon tax, and its optimal level is more sensitive to the structure of the innovation process.
\end{abstract}

Key Words: Carbon tax, Incentive, Innovation, Mandates, Renewable energy, R\&D, Welfare.

JEL codes: H23, O31, Q42, Q55, Q58

May 28, 2015

* Matthew S. Clancy is a Ph.D. candidate, Department of Economics, Iowa State University, Ames, IA 50011. GianCarlo Moschini is Professor and Pioneer Chair in Science and Technology Policy, Department of Economics and Center for Agricultural and Rural Development, Iowa State University, Ames, IA 50011. Clancy was supported by a USDA NIFA National Needs Fellowship grant, and Moschini acknowledges the support of the Pioneer Chair in Science and Technology Policy. 


\section{Introduction}

Given the threat of global climate change resulting from greenhouse gas emissions, there is considerable interest in policies that aim to facilitate the substitution of renewable energy for conventional fossil fuels. In addition to correcting the market failure of a pollution externality, it is recognized that policies that promote adoption of renewable energy also have the potential to affect incentives for innovation in better renewable technologies. Indeed, because of the scale of the problem at hand, the role of research and development $(\mathrm{R} \& \mathrm{D})$ activities is crucial if a sustainable long-term solution is to be attained (Barrett 2009, Popp 2010). The process of innovation is itself fraught with market failures, and most policy tools are imperfectly suited to tackle both the pollution mitigation objective and the innovation challenge (Jaffe, Newell and Stavins 2003). A considerable body of work has analyzed the performance of alternative environmental policies vis-à-vis their impact on innovation. The dichotomy of prices versus quantity tools is a recurrent theme in this literature, which has privileged the comparison of carbon taxes with (tradable) pollution permits. The presence of multiple market failures has tended to make ranking of various policies options inconclusive (Fischer, Parry and Pizer 2003), although the balance of evidence reviewed by Requate (2005) appears to favor price-based policies. Existing analytical models, however, do not seem to apply well to a type of quantity tools that has become increasingly popular in recent years: quantity "mandates" that require a certain fraction of consumption to be accounted for by renewable energy.

Mandates set a target for renewable energy production, and it falls upon the producers and suppliers of energy to meet this quota. Renewable portfolio standards are a prominent example of this kind of policy and, as of 2011, were used in 27 US states (Delmas and Montes-Sancho 2011), and six European countries (Haas et al. 2011). Renewable portfolio standards mandate that suppliers of electricity source a set percentage of electricity from renewable sources such as solar, wind, biomass, and hydroelectric providers (Holland 2012). A more direct example is perhaps provided by US biofuel policies. The use of mandates is one of the distinctive features of the 2007 Energy Independence and Security Act (EISA), which envisioned overall biofuel use as transportation fuel in the United States to grow to 36 billion gallons by 2022 (Moschini, Cui and Lapan 2012). Whereas the ability of such mandates to engineer increased adoption of renewable energy is clear, their

effectiveness at reducing pollution has been at times controversial, as has the impact on welfare (because of unintended effects, e.g., the food vs. fuel debate) (Janda, Kristoufek and Zilberman 2012). Even less is known about the other critical feature noted above: the ability of corrective 
policies to induce environmental innovation. In this paper we undertake to study this particular question: just how effective are mandates at promoting innovation?

Interest in the question posed in this paper can be highlighted by the experience with US biofuel policies. Mandates have been effective at spurring the growth of the corn-based ethanol industry, which steadily accumulated the capacity required to produce the mandated targets in a timely fashion. But in order to meet the ambitious targets set out by EISA, a major role is envisioned for advanced biofuels such as cellulosic ethanol: 21 of the 36 billion gallons of biofuels mandated by 2022 are supposed to come from advanced biofuels. The experience, so far, has been disappointing: for several years now, the US Environmental Protection Agency (EPA) has essentially waived the mandate for cellulosic ethanol. In their latest ruling, for 2014 the EPA proposed to blend a mere 17 million gallons of cellulosic ethanol into the fuel supply, down from the EISA statutory requirement of 1,750 million gallons (EPA 2013). An obvious distinction between corn-based ethanol and cellulosic ethanol is that the former is produced with a mature technology, whereas the latter requires new technological breakthrough to make it scalable and commercially viable. For advanced biofuels, therefore, mandates were really supposed to spur sufficient innovation. Is that a legitimate expectation for a policy tool such as mandates? And, if innovation is the crux of the issue, how do mandates compare with a more standard environmental policy tool such as a carbon tax?

In this paper we analyze the scope of mandates as a tool to promote environmental innovation. Specifically, we consider a market with clean and dirty energy sources that are close substitutes, e.g., renewable energy and fossil fuels. The dirty energy imposes a negative externality on society. The clean energy has no such externality, and the cost of producing it can be lowered through R\&D. Following the approach introduced by Parry (1995), Laffont and Tirole (1996) and Denicolo (1999), we view the R\&D sector as separate from the production sector adopting the new technology. The profit opportunity that motivates innovators is directly influenced by environmental policies that penalize dirty energy use or reward clean energy use, and it is mediated by patents. The latter are known to permit only imperfect appropriability of the innovation's benefits, which generally leads to under-provision of R\&D. Indeed, for environmental innovations where the underlying externality is not fully internalized by private agents, this under-provision problem is believed to be most acute (Jaffe, Newell and Stavins 2005). Because we wish to emphasize the innovation challenges posed specifically by environmental externalities, rather than the general problem of spurring innovation in a market setting, here we take the second-best nature of patents as given and ignore other policy 
instruments that deal with innovation in general (Clancy and Moschini 2013). In this setting, no environmental policy measure can lead to a first best outcome by itself. The effectiveness of mandates at spurring environmental innovation, therefore, is best understood as compared to a welldefined alternative. Hence, we compare the innovation effects of a mandate with those of a carbon tax (the standard implementation tool of price-based policies).

The incentive to innovate induced by environmental policies has been studied either in a deterministic (Denicolo 1999; Fischer, Parry and Pizer 2003; Scotchmer 2010) or stochastic setting (Biglaiser and Horowitz 1994; Parry 1995; Laffont and Tirole 1996). To fit the distinctive policy challenge of bringing about new technologies such as advanced biofuels, a stochastic framework seems most appropriate. Accordingly, in the model we develop, a firm that invests in R\&D gets an independent draw of a cost-reducing technology for the production of renewable energy. We model both the case of a single innovator and the case of multiple innovators. For the latter case, innovators engage in a form of Bertrand competition, so that the firm with the best innovation is the exclusive licensor, but the price that can be charged is constrained by the firm with the next-best innovation. Multiple innovators can raise welfare through two channels: an increase in the number of innovating firms increases the expected quality of the best innovation that will discovered, and, the expost royalty rate for the best innovation is reduced by the presence of competitors. ${ }^{1}$ This formulation allows us to capture, in an effective and explicit way, the spillover effect of innovations, and the associated imperfect appropriability problem that is one of the roots of R\&D underprovision. Another feature of our model is a plausible presumption about the innovation process: when they choose R\&D investments firms have better information than policy makers do when they set the policy. This information asymmetry may stem either from the specialized knowledge of firms, or from the policy-maker's need to set the policy several years in advance, so that it cannot respond to scientific and technological developments (as in the case of the advanced biofuels mandate). To evaluate and compare policies, however, we take the ex ante perspective of policy makers who know the distribution of innovation prospects but do not know the actual information possessed by innovators.

\footnotetext{
${ }^{1}$ Because of our focus on R\&D incentives, we do not attempt to distinguish between the stages of innovation and diffusion that customarily play distinct roles in this setting (Popp, Newell and Jaffe 2010). In our model diffusion is implicitly assumed to be costless, except for the license fee charged by the innovator).
} 
Two additional features of our modeling framework deserve a brief discussion. First, we assume that the marginal environmental damage of the externality is constant. This commonly invoked condition, together with the assumption that the conditional distribution of firms' innovation outcomes is uniform, simplifies the analysis considerably and permits the derivation of explicit results. In addition to its analytical attractiveness, this assumption might be appropriate for the case of renewable energy that motivates our analysis. For example, cellulosic ethanol can only address a small portion of the overall energy needs of the economy, and innovations in this area are likely to have a limited impact on the overall level of carbon emission. Furthermore, the energy sector's emissions are small relative to the cumulative stock of emissions, which is what ultimately drives climate change. Hence, a linear damage function is arguably appropriate in our context, at least as a local approximation to a convex damage function. A second modeling issue arises because of the dynamic implications of R\&D incentives. The challenge of devising optimal policies in this context has to deal with Kydland and Prescott's (1977) time consistency problem: once new less-polluting technologies are developed, policy makers might want to change environmental rules, and this ex post policy adjustment alters the innovator's $e x$ ante incentives. Whether or not policy makers can credibly commit to an environmental policy course, therefore, is of considerable importance (Laffont and Tirole 1996, Denicolo 1999). In our model, having assumed constant marginal environmental damages, the naïve carbon tax that we consider in the analytical section is actually unaffected by the realization of the innovation (Kennedy and Laplante 1999). The optimal mandate and the optimal carbon tax that we consider in the numerical analysis, on the other hand, are not time-consistent. When comparing the performance of mandates with the carbon tax, however, we assume that policymakers have committed to their policy.

Our results show that mandates can in fact improve upon laissez faire, and that the prospect of innovation is essential for the desirability of mandates. However, mandates suffer from several limitations and are generally inferior to a carbon tax. We find that a mandate, besides leading to a sub-optimal static equilibrium compared to a carbon tax, also leads to different innovation outcomes. In particular, we find that a mandate is relatively good at incentivizing incremental innovation but a poor spur to breakthrough innovation, as compared with a carbon tax. Mandates also lead to inferior welfare outcomes relative to carbon taxes. In addition to welfare and expected technology results, we highlight the differential distributions of realized technology that different 
policies can induce. Specifically, we show that carbon taxes induce a more disperse distribution of innovation (either very good or none at all) than a mandate.

The rest of the paper is organized as follows. In Section 2 we lay out our model for the case of a single innovator. Section 3 explicitly compares the mandate policy with the naïve carbon tax when there is one innovator. In Section 4, we extend the model to allow for free entry into the innovation sector. Section 5 compares the mandate policy with the carbon tax when there are multiple innovators. Section 6 uses a numerical simulation to compare the performance of the two policy instruments (mandate and carbon tax) when their level is set "optimally," i.e., accounting for both the externality correction and innovation. This permits us to consider more general welfare conclusions than those derived in the analytical section, and to explore the robustness of our results to the relaxing of certain conditions. We conclude with a summary of our findings, additional discussion of policy implications, and some thoughts about further research.

\section{The Model}

We model innovation as a purposeful economic activity undertaken by firms seeking to profit from licensing the implementation of their successful ideas. The innovation of interest is modeled as a replacement technology, rather than an abatement technology (another common approach to study environmental innovations). Specifically, we focus on the introduction of a new product that can substitute for an existing product that produces a negative environmental externality. The new product is cleaner-in fact, without much loss of generality, we will assume that this new product has zero emissions. Our modeling of innovation as a replacement technology is consistent with the approach of Denicolo (1999), Laffont and Tirole (1996), and Scotchmer (2011), among others. This approach has also recently been used in the context of climate change (Acemoglu et al. 2012), and fits well the renewable versus conventional fossil fuel context. A distinctive feature of our approach, however, is to model innovation explicitly as a stochastic process. As in Scotchmer (2004), we postulate that innovators decide whether or not to conduct R\&D after obtaining a draw from the space of ideas. We extend this approach by assuming that these draws give the innovator only a signal about the likely quality of innovation, but the latter remains stochastic. Furthermore, whereas innovators are assumed to observe the signal of technological opportunity prior to making the R\&D investment, we presume that the policy setting is determined in advance of the realization of this signal. When comparing alternative policy instruments (carbon tax and mandates), the relevant $e x$ 
ante perspective therefore is that of the policy maker, who knows the distribution of all possible signals but does not observe the realization that drives innovators' decisions. Our stochastic model has other attractive features, including that of permitting an explicit characterization of the multiple innovators setting. Furthermore, this approach is amenable to numerical analysis, which we use to supplement the analytical results.

Consumers are assumed to have quasilinear preferences for a numeraire good and energy $Q$, with the aggregate inverse demand for energy given by $P(Q)$, where $P^{\prime}(Q)<0$. There are two forms of energy: an older and dirty form of energy, denoted $Q_{1}$, and a new renewable and clean form of energy, denoted $Q_{2}$. These two sources of energy are perfect substitutes from the consumer's perspective, and thus we can represent total energy used as $Q=Q_{1}+Q_{2}$. Total damage from emission is $X=x Q_{1}$, where $x$ is the (constant) marginal environmental damage rate. A feature of the innovation context that we wish to model is the fact that the renewable source of energy in question is unlikely to be able to completely supplant the conventional source, and, relative to the latter, it is expected to be at a scalability disadvantage in both production and distribution. To capture this asymmetry, we assume that the production of the older product displays constant returns to scale at the industry level, whereas renewable energy is produced under decreasing returns to scale at the industry level. Furthermore, whereas the analysis that we present does not restrict the shape of the inverse demand function $P(Q)$, to obtain clear results (especially for the multiple innovators case) we find it convenient to restrict attention to linear industry marginal cost schedules. More specifically, if $C_{1}\left(Q_{1}\right)$ and $C_{2}\left(Q_{2}, \theta\right)$ denote the industry cost functions for the two products, conventional energy is assumed to be produced by a perfectly competitive industry with constant marginal cost, i.e.,

$$
\frac{\partial C_{1}\left(Q_{1}\right)}{\partial Q_{1}}=c_{1}
$$

whereas the new clean technology displays an upward-sloping marginal cost function:

$$
\frac{\partial C_{2}\left(Q_{2}, \theta\right)}{\partial Q_{2}}=c_{2}-\theta+Q_{2}
$$


where $c_{1}$ and $c_{2}$ are fixed parameters, with $c_{2}>c_{1}$, and $\theta$ is an index of technological progress that captures the impact of innovation. ${ }^{2}$ This is illustrated in Figure 1.

\section{Figure 1. Conventional and renewable energy: Innovation, supply and demand}

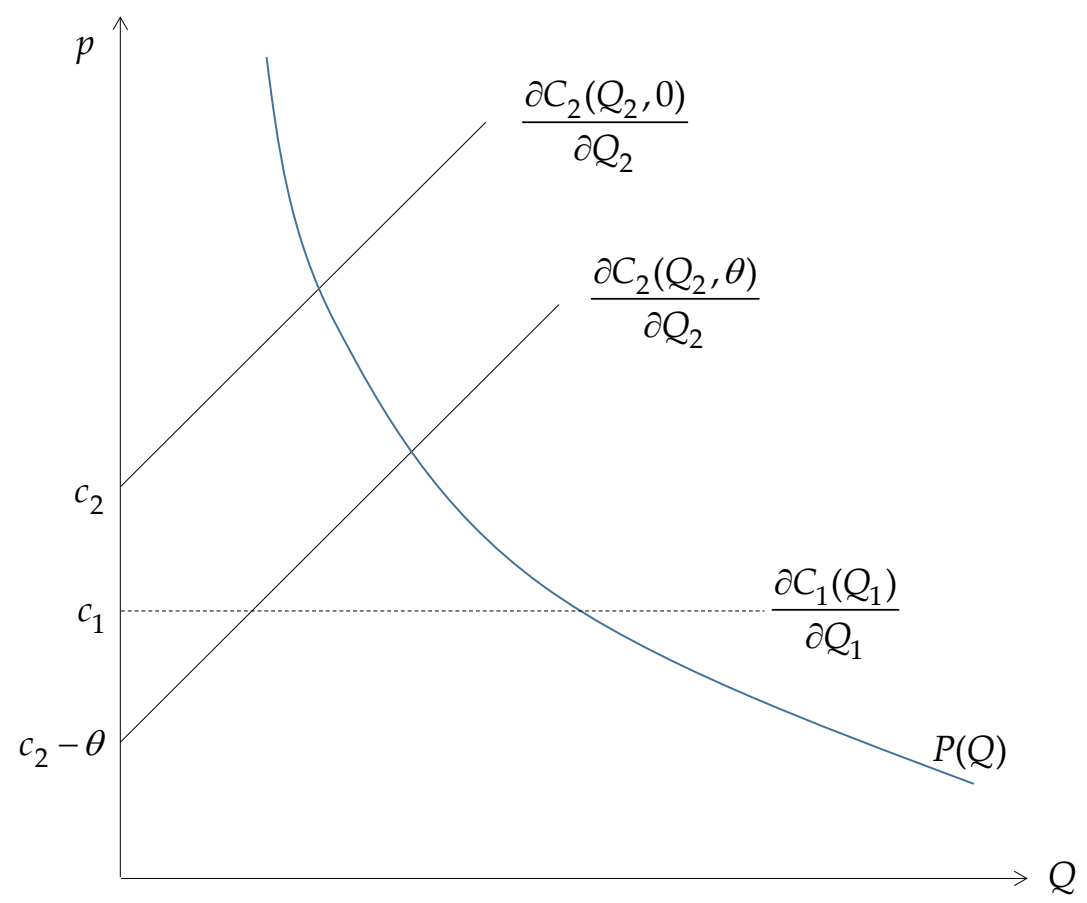

Initially, $\theta=0$. The innovation process consist of $\mathrm{R} \& \mathrm{D}$ projects, each of which can produce a draw $\theta \geq 0$ upon incurring a (fixed) cost $k>0$. As exemplified in (2), innovation lowers the marginal cost of producing renewable energy. More specifically, to develop a new production technology, innovators first receive a draw of $\omega$ from a known cumulative probability distribution $G(\omega)$ with domain $[0, \bar{\omega}]$. Given $\omega$, the researcher may choose to pay $k$ to obtain a draw of $\theta$ from the conditional distribution function $F(\theta \mid \omega)$. Whereas the distribution function $G(\omega)$ is unrestricted, apart from the standard monotonicity and continuity properties, the analytical results that we present rely on postulating that $F(\theta \mid \omega)$ is a uniform distribution. In particular, the density function of this distribution is:

\footnotetext{
${ }^{2}$ Linearity of the marginal cost schedule is the main assumption in (2). Conditional on that, setting the slope equal to one is achieved without further loss of generality by choice of the units of measurement for $Q$.
} 


$$
f(\theta \mid \omega)=\left\{\begin{array}{cc}
1 / \omega & \text { if } \theta \in[0, \omega] \\
0 & \text { otherwise }
\end{array}\right.
$$

The parameter $\omega$ characterizes technological opportunity, such that the expected value and upper bound of the innovation draw $\theta$ are increasing in $\omega$. But because even the most promising innovation can fail, the lower bound on innovation quality is always zero. We assume that $\omega$ is private information known to innovators, but that the functions $G(\omega)$ and $F(\theta \mid \omega)$ are common knowledge.

Innovation is understood as producing know-how, and this knowledge is patentable. Innovators produce a blueprint for a new technology, and can license these blueprints to the competitive production sector that produces renewable energy. Licensing is presumed to take the forms of a fixed royalty rate $r$ per unit of $Q_{2}$. In this setting, we want to evaluate the effectiveness of mandates as a policy tool to both ameliorate the externality and promote innovation. For a meaningful benchmark, we compare mandates with a carbon tax and, naturally, both policies with the laissez faire situation without any policy. For clarity, we start with the latter cases.

\subsection{Innovation under laissez faire}

For the characterization of both the laissez faire situation (absence of government policy), and the case of a carbon tax considered next, the inverse residual demand curve facing clean the production sector can be written as:

$$
P_{2}\left(Q_{2}\right)=\left\{\begin{array}{lc}
c_{1}+t & \text { if } Q_{2} \leq P^{-1}\left(c_{1}+t\right) \\
P(Q) & \text { otherwise }
\end{array}\right.
$$

where $t$ denotes the carbon (per unit of dirty energy). For the laissez faire case of this section, $t=0$. In such a case, if clean energy is priced below the cost of dirty energy $\left(c_{1}\right)$, then it captures the entire market; if it is priced above the cost of dirty energy, demand for clean energy falls to zero; and, any

quantity $Q_{2} \in\left[0, P^{-1}\left(c_{1}\right)\right]$ can be sold when clean energy is priced at the cost of dirty energy.

As noted earlier, the realistic scenario is that the new renewable energy source does not completely replace the pre-existing conventional source. That is, the innovation is "nondrastic" in Arrow's 
(1962) terminology. The following condition, which we maintain throughout (unless otherwise stated), will guarantee this outcome.

Condition 1. The upper bound on technological innovation satisfies $\bar{\omega} \leq c_{2}-c_{1}+P^{-1}\left(c_{1}\right)$.

In this section we assume that there is only one firm capable of innovating (this assumption is relaxed in later sections). To characterize the innovator's decision problem, consider first the licensing stage for an arbitrary innovation of quality $\theta$. The innovator sets the per-unit royalty $r$ to maximizes profits, conditional on the adoption constraint by the competitive clean production sector (which, given the foregoing considerations, faces a perfectly elastic demand at price equal to $\left.c_{1}\right)$. Thus, the innovator's optimal royalty maximizes $r Q_{2}$, where the demand from the competitive adopting clean energy sector, for $Q_{2}>0$, satisfies $c_{2}-\theta+Q_{2}+r=c_{1}$. When $c_{2}-\theta \geq c_{1}$ there is no strictly positive license fee that can result in any adoption. In such a case, the innovation is insufficient to be cost-competitive with the dirty technology. Thus, licensing only occurs if the innovative step is sufficiently large. More specifically, $\hat{\theta} \equiv c_{2}-c_{1}$ defines the minimum innovative step beyond which the innovation becomes profitable. For $\theta \geq \hat{\theta}$, optimal royalty is $r^{*}=(\theta-\hat{\theta}) / 2$, and at this price the quantity licensed is $Q_{2}=(\theta-\hat{\theta}) / 2$. The maximum profit an innovator with technology $\theta$ can obtain, when $\theta \geq \hat{\theta}$, is $\pi=(\theta-\hat{\theta})^{2} / 2$ (and, of course, $\pi=0$ when $\theta<\hat{\theta}$ ). A researcher with technological opportunity $\omega$ expects the innovation to yield zero profit whenever $\theta<\hat{\theta}$, which happens with probability $\hat{\theta} / \omega$, and thus to make positive profit with probability $1-\hat{\theta} / \omega$. Expected profit conditional on $\omega$, denoted $\pi(\omega)$, can therefore be written as:

$$
\pi(\omega)=\left(1-\frac{\hat{\theta}}{\omega}\right)\left[\frac{1}{4(\omega-\hat{\theta})} \int_{\hat{\theta}}^{\omega}(\theta-\hat{\theta})^{2} d \theta\right]=\frac{(\omega-\hat{\theta})^{3}}{12 \omega}
$$

Because the innovator is assumed to be risk neutral, she will choose to conduct research whenever the expected profits from licensing exceed the costs of $\mathrm{R} \& \mathrm{D}$, which occurs when $\pi(\omega) \geq k$. This implies the existence of a threshold $\hat{\omega}>\hat{\theta}$, which satisfies $\pi(\hat{\omega})=k$, such that innovation is undertaken if and only if $\omega>\hat{\omega}$. 
To understand how innovation affects welfare we note that, given the presumption that innovation is non-drastic, renewable energy is always priced at $c_{1}$ (when developed). This means that the total quantity of energy $Q$, and consumer surplus (denoted $S_{0}$ ), are not affected by innovation. Instead, innovation affects the share of energy produced by renewable sources, and reduces the status quo ante damage from externalities (denoted $\mathrm{X}_{0}$ ) by $x Q_{2}$. Recall that, when there is innovation, $Q_{2}=(\theta-\hat{\theta}) / 2$, and thus $E\left[Q_{2}\right]=(\omega-2 \hat{\theta}) / 4$. License revenues are given in equation (5). Clean

producer profits can be shown to be $(\omega-\hat{\theta})^{3} / 24 \omega$ in expectation. All told, therefore, expected welfare in the absence of government intervention is

$$
E[W]=S_{0}-X_{0}+\int_{\hat{\omega}}^{\bar{\omega}}\left\{\left[\frac{(\omega-\hat{\theta})^{3}}{12 \omega}+\frac{(\omega-\hat{\theta})^{3}}{24 \omega}+x\left(\frac{\omega-2 \hat{\theta}}{4}\right)-k\right]\right\} d G(\omega)
$$

where the third term in the RHS of (6) is the expected contribution of innovation to welfare.

\subsection{The naïve carbon tax}

It is well known that laissez-faire expected welfare, in this setting, is suboptimal for two reasons: the uncompensated negative externality means there is excess production of dirty fuel, relative to the social optimum; and, the extent of innovation is insufficient. The canonical solution to an externality of the type posited is a carbon tax on the dirty fuel. Because use of fossil fuels incurs a social cost $x$ per unit consumed, if we ignore the prospect of innovation the tax should be set at $t=x$. We will use this "naïve" carbon tax as the benchmark in our analytical results, and consider the optimal carbon tax (which also accounts for the prospect of innovation) in the numerical section. With a unit $\operatorname{tax} t$ on fossil fuel, clean producers face an inverse residual demand curve given in (4). As illustrated in the previous section, some innovations may be of insufficient size to be competitive, so that the characterization of the impact of innovation needs to always account for the probability that an innovation of sufficient size actually materializes. To simplify the exposition, and without much loss of generality, it is convenient to maintain the following condition.

Condition 2. The pre-innovation renewable energy technology satisfies $c_{2}=c_{1}+x$.

This parametric case restricts attention to the situation where the renewable energy source is on the brink of being competitive, given an appropriately tax on the externality posed by the dirty 
technology. Condition 2 guarantees that the optimal supply of renewable energy is positive for any $\theta>0$ (i.e., the subsequent analysis can drop the parameter $\hat{\theta}$ corresponding to the minimum inventive step).

Given Condition 2, the optimal license fee and equilibrium quantity of renewable energy satisfy $r^{*}=Q_{2}=\theta / 2$. The maximum profit for an innovator possessing an innovation of quality $\theta$, given the existence of the carbon tax $t$, is: $\pi_{t}=\theta^{2} / 4$. The innovator's expected profits conditional on technological opportunity, denoted $\pi_{t}(\omega)$, is given by:

$$
\pi_{t}(\omega)=\frac{\omega^{2}}{12}
$$

Given the existence of a tax $t$, the threshold $\hat{\omega}_{t}$ for R\&D to be conducted satisfies $\pi_{t}\left(\hat{\omega}_{t}\right)=k$, and thus $\hat{\omega}_{t}=\sqrt{12 k}$. It is readily verified that this threshold is lower than under laissez-faire, i.e., $\hat{\omega}_{t}<\hat{\omega}$. Similarly to the laissez-faire situation, with a carbon tax a non-drastic innovation does not affect the total quantity of energy nor consumer surplus (here denoted $S_{0}^{*}$ ). Innovation now improves welfare through its effect on the cost of producing clean fuel, via license profit to the innovator and producer surplus to clean producers. The former was derived in (7). The producer surplus of clean producers can be shown to be $\theta^{2} / 8$, or $\omega^{2} / 24$ in expectation. Combining all elements, expected welfare with innovation, given the carbon $\operatorname{tax} t=x$, is:

$$
E[W]=S_{0}^{*}+\int_{\hat{\omega}_{t}}^{\bar{\omega}}\left[\frac{\omega^{2}}{12}+\frac{\omega^{2}}{24}-k\right] d G(\omega)
$$

When compared with (6) we note that the term related to the environmental externality is absent. But welfare is still suboptimal because of the standard appropriability problem that is only partially solved by patents (innovation in underprovided from a social point of view).

\subsection{Mandates}

A mandate policy specifies a minimum amount a renewable energy to be used as part of the production/consumption portfolio. Such a policy can be modeled either as a proportional or an absolute mandates. With an absolute mandate, distributors must ensure that $Q_{2} \geq \hat{Q}$, where $\hat{Q}$ is 
the mandated minimum quantity of total renewable energy in use. With a proportional mandate, distributors are required to ensure that the total quantity of renewable energy $Q_{2}$ amounts to (at least) a given proportion of the total energy $Q \equiv Q_{1}+Q_{2}$ (e.g., 10 percent). Which of these two modeling approaches are employed does not matter for some questions (e.g., de Gorter and Just 2009, Lapan and Moschini 2012). ${ }^{3}$ In our innovation context, which of these two approaches one uses does entail some modeling differences. Whereas the substantive conclusions one reaches are not affected by this choice, it turns out that an absolute mandate permits a crisper analysis (because it is easier to formalize the results without specifying a particular form for the aggregate energy inverse demand function $P(Q))$. Hence, we proceed by explicitly modeling an absolute mandate.

The implementation of the mandate postulates the existence of a competitive blending sector that combines energy from two sources: conventional energy, sourced at the constant marginal cost $c_{1}$, and renewable energy, priced at its (increasing) marginal cost $\partial C_{2} / \partial Q_{2}=c_{2}-\theta+r+Q_{2}$. The zero profit condition for the competitive blending sector ensures that, for a given mandate $\hat{Q}$ of renewable energy and corresponding quantity $(Q-\hat{Q})$ of conventional energy, consumers are charged a price $\tilde{P}(Q)$ that is the weighted average of the energy input costs:

$$
\tilde{P}(Q) \equiv c_{1} \frac{Q-\hat{Q}}{Q}+\left(c_{2}-\theta+r+\hat{Q}\right) \frac{\hat{Q}}{Q}
$$

This formulation presumes that the mandate is binding (typically the case of interest), which is the case whenever the mandate $\hat{Q}$ is such that $\left(c_{2}-\theta+r+\hat{Q}\right)>c_{1}$. The issue of feasibility of the mandate should be noted at this juncture. Feasibility is relevant because how much consumers are willing to buy at the blend price is still governed by the (inverse) demand function $P(Q)$. Because consumers (and competitive suppliers) cannot be coerced, not every arbitrary mandate $\hat{Q}$ is feasible.

Therefore, in what follows we will assume that the mandate is feasible.

\footnotetext{
${ }^{3}$ US biofuel mandates can be rationalized as either absolute or proportional mandates. In particular, the EISA legislation specifies absolute mandates for various biofuels. The implementation of such mandates, however, takes the form of proportional mandates imposed on obligated parties. These proportional mandates are set annually by the EPA so that the statutory absolute mandates specified by EISA are met, given the prevailing demand conditions (Schnepf and Yacobucci 2013).
} 
Condition 3. The mandate is feasible in that there is an equilibrium total quantity that solves $\tilde{P}\left(Q^{*}\right)=P\left(Q^{*}\right)$ and satisfies $Q^{*} \geq \hat{Q}$.

Figure 2 illustrates the case of a feasible mandate $\left(\hat{Q}^{\prime}\right)$ and that of an unfeasible mandate $\left(\hat{Q}^{\prime \prime}\right)$. If we define $\bar{Q}$ such that $\partial C_{2}(\bar{Q}, 0) / \partial Q_{2}=P(\bar{Q})$, then a sufficient condition to ensure feasibility of the mandate is that $\hat{Q} \leq \bar{Q}$. This requirement is not necessary, however. For a fixed $\hat{Q}$, and given that $c_{2}+\hat{Q}>c_{1}$, the blend price $\tilde{P}(Q)$ is decreasing in $Q$ and asymptotically approaches $c_{1}$ from above as $Q$ increases. So, it is quite possible for the equilibrium condition $\tilde{P}\left(Q^{*}\right)=P\left(Q^{*}\right)$ to be satisfied with $Q^{*} \geq \hat{Q}$ for some $\hat{Q}>\bar{Q} .^{4}$

Figure 2. Feasible and unfeasible mandates

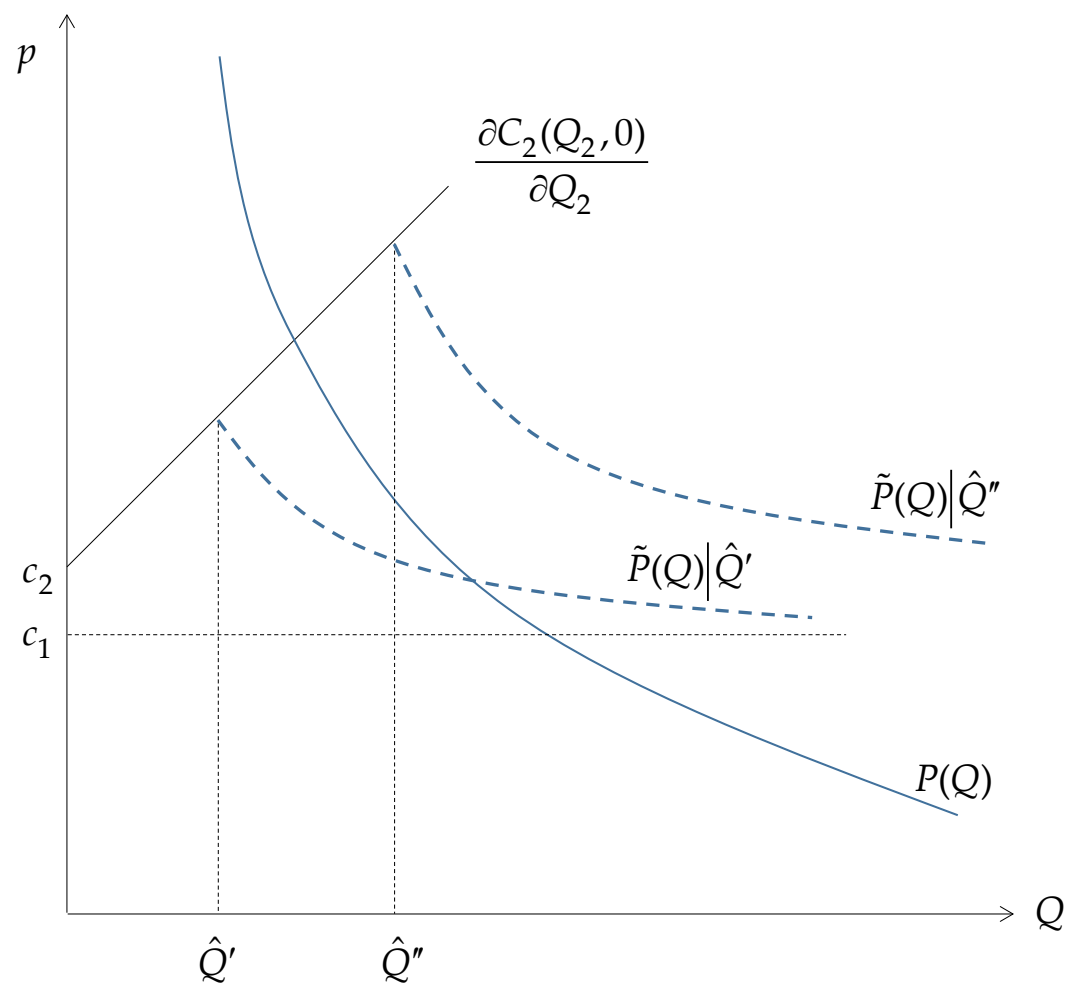

${ }^{4}$ When the mandate exceeds $\bar{Q}$ there may be multiple solutions to $\tilde{P}\left(Q^{*}\right)=P\left(Q^{*}\right)$ (in which case one may appeal to stability conditions to select the relevant equilibrium) or none at all, depending on the shape of the market inverse demand function $P(Q)$. 
For the analytical results that follow, we wish to concentrate on the policy-relevant case when, postinnovation, the mandate is binding (we will relax this assumption in the numerical analysis of Section 6). In such a case, an innovating firm in possession of technology $\theta$ chooses the royalty rate to maximize $r \hat{Q}$, such that $c_{2}-\theta+\hat{Q}+r \leq c_{2}+\hat{Q}$. This constraint represents the option that clean producers have to meet the mandate by using the pre-innovation technology (for which $\theta=0$ ). Clearly, the profit-maximizing license is $r^{*}=\theta$. The profit attainable by an innovator with technology $\theta$, under a binding mandate, is therefore $\pi_{m}=\theta \hat{Q}$. What parametric conditions would ensure that the mandate is binding? When the best possible technology is such that $\bar{\omega} \leq \hat{\theta} \equiv c_{2}-c_{1}$, then obviously the mandate is always binding. Otherwise, we note that for the innovator to exceed the mandate the new technology would need to be priced to be competitive with the dirty technology, which is available at marginal cost $c_{1}$. From the laissez-faire section 2.1, the profit of the innovator with such a pricing strategy is $\pi=(\theta-\hat{\theta})^{2} / 2$. If this profit, for the best possible innovation $\theta=\bar{\omega}$, is no larger than $\pi_{m}$ given above, then the mandate will be binding. Hence, when $\bar{\omega}>c_{2}-c_{1}$, to guarantee that the mandate is always binding it suffices to assume:

Condition 4. The mandate satisfies $\hat{Q} \geq\left(\bar{\omega}-\left(c_{2}-c_{1}\right)\right)^{2} / 4 \bar{\omega}$ and thus is always binding.

Given that the mandate is binding, the expected profit of the innovator with technological opportunity $\omega$, denotes $\pi_{m}(\omega)$, is:

$$
\pi_{m}(\omega)=\omega \hat{Q} / 2
$$

The lower bound for technological opportunity under which innovation occurs, denoted $\hat{\omega}_{m}$, solves $\pi_{m}\left(\hat{\omega}_{m}\right)=k$, and therefore $\hat{\omega}_{m}=2 k / \hat{Q}$. This threshold is increasing in the cost of R\&D and decreasing in the mandate. Under a mandate policy, therefore, $\mathrm{R} \& \mathrm{D}$ occurs with probability $1-G\left(\hat{\omega}_{m}\right)$. Moreover, by Condition $4, \hat{\omega}_{m} \leq \hat{\omega}$, so that the probability of R\&D is higher under a mandate than the laissez-faire case.

Concerning the impact of innovation on welfare we again find that, because neither the price nor quantity of energy produced changes, there is no change in consumer surplus, now denoted $S_{0}^{m}$, nor 
the damage from the externality, denoted $X_{0}^{m}$. In this case, the producer surplus $\Pi_{0}^{m}$ of clean firms is also unaffected by innovation, because the innovator fully appropriates the reduction in cost brought about by the innovation. Accordingly, the change in welfare due to innovation is purely derived from licensing profits less R\&D costs, so that expected welfare under a mandate is given by:

$$
E[W]=S_{0}^{m}+\Pi_{0}^{m}-X_{0}^{m}+\int_{\hat{\omega}_{m}}^{\bar{\omega}}\left(\frac{\omega \hat{Q}}{2}-k\right) d G(\omega)
$$

While the static welfare $S_{0}^{m}+\Pi_{0}^{m}-X_{0}^{m}$ may be suboptimal, the extent of induced innovation, given this policy, is optimal, because the threshold $\hat{\omega}_{m}$ is exactly determined by where the term under the integral is equal to zero. Moreover, equation (11) implies:

RESULT 1. The welfare maximizing quantity mandate is increased when the social planner takes into account its impact on innovation.

To see why this is the case, consider the case where innovation is not possible. In this case, the optimal static mandate $\hat{Q}_{0}$ is chosen so that:

$$
\frac{\partial S_{0}^{m}}{\partial \hat{Q}}+\frac{\partial \Pi_{0}^{m}}{\partial \hat{Q}}-\frac{\partial X_{0}^{m}}{\partial \hat{Q}}=0
$$

where the sign of the derivative is given below each term. This first order condition pins down the optimal mandate in the absence of innovation (assuming the usual concavity conditions are satisfied). However, incorporating innovation changes the first order condition such that the optimal mandate, denoted $\hat{Q}_{0}^{I}$, now solves:

$$
Z\left(\hat{Q}_{0}^{I}\right) \equiv \frac{\partial S_{0}^{m}}{\partial \hat{Q}}+\frac{\partial \Pi_{0}^{m}}{\partial \hat{Q}}-\frac{\partial X_{0}^{m}}{\partial \hat{Q}}+\int_{(+)}^{\bar{\omega}} \frac{\omega}{\hat{\omega}_{m}} \frac{(+)}{2} d G(\omega)-\left\{\frac{\omega \hat{Q}}{2}-k\right\} \frac{\partial \hat{\omega}_{m}}{\partial \hat{Q}}=0
$$

It is apparent that, when evaluated at $\hat{Q}_{0}, Z\left(\hat{Q}_{0}\right)>0$. This implies that welfare, when evaluated at $\hat{Q}_{0}$, is increasing in $\hat{Q}$, so that the mandate should be increased relative to the optimal mandate 
without innovation. The intuition here is that innovation increases welfare, and a larger mandate increases the incentive to innovate.

\section{Mandate vs. Carbon Tax: A Comparison}

To evaluate the effectiveness of mandates vis-à-vis the alternative of a carbon tax, it is necessary that the two policies be calibrated to make the comparison meaningful. The benchmark we select initially is to require that the two policies yield the same probability that R\&D be undertaken by the innovator, which requires that thresholds of technological opportunity be the same under the two policies, i.e., $\hat{\omega}_{t}=\hat{\omega}_{m}$. The threshold under a carbon tax $t=x$ that fully internalizes the social cost of conventional energy, given Condition 2 , was shown to be $\hat{\omega}_{t}=\sqrt{12 k}$, whereas under a mandate the innovation threshold is $\hat{\omega}_{m}=2 k / \hat{Q}$. Hence, the comparable mandate is $\hat{Q}=\sqrt{k / 3}$.

Remark 1. When the mandate $\hat{Q}$ is calibrated to yield the same probability of R\&D as the carbon tax, the expected value of the technology used by clean producers is the same under both policies.

This observation simply follows from the fact Condition 2 entails that, expost, all technologies are used by clean producers, under either taxes or mandates, for any $\omega \geq \hat{\omega}_{t}=\hat{\omega}_{m}$.

Moreover, we also note the following feature of mandates.

Remark 2. As the cost of $R \& D$ increases, the level of the mandate must be progressively increased in order to attain the same probability of R\&D as a fixed carbon tax.

Whereas the above remarks show that each policy is capable of inducing innovation at the same rate, the welfare implications of these policies differ.

RESULT 2. When a mandate is chosen so that $\mathrm{R} \& \mathrm{D}$ is equally probable under a mandate or a carbon tax, then expected welfare is higher with a carbon tax.

The proof of this result starts by noting that Result 2 will hold so long as:

$$
S_{0}^{*}+\int_{\hat{\omega}_{t}}^{\bar{\omega}}\left\{\frac{\omega^{2}}{12}+\frac{\omega^{2}}{24}-k\right\} d G(\omega) \geq S_{0}^{m}+\Pi_{0}^{m}-X_{0}^{m}+\int_{\hat{\omega}_{m}}^{\bar{\omega}}\left\{\frac{\omega \hat{Q}}{2}-k\right\} d G(\omega)
$$


We note at this juncture that a mandate $\hat{Q}>0$ is incapable of achieving the first best allocation in the absence of innovation. Given the parameterization of Condition 2, the optimal allocation in the absence of innovation has $P\left(Q_{1}\right)=c_{1}+x$ and $Q_{2}=0$. This mix of energy inputs is impossible to achieve with an instrument that only requires $Q_{2} \geq \hat{Q}$. Because the first-best allocation (absent innovation) is attained by a carbon tax, it must be that $S_{0}^{*}>S_{0}^{m}+\Pi_{0}^{m}-X_{0}^{m}$. Hence, Result 2 will hold when the gains from innovation under the carbon tax exceed those under the mandate, i.e.,

$$
\int_{\hat{\omega}_{t}}^{\bar{\omega}}\left\{\frac{\omega^{2}}{12}+\frac{\omega^{2}}{24}-k\right\} d G(\omega) \geq \int_{\hat{\omega}_{t}}^{\bar{\omega}}\left\{\frac{\omega \sqrt{k / 3}}{2}-k\right\} d G(\omega)
$$

where we have exploited the fact that the mandate is calibrated so that $\hat{\omega}_{m}=\hat{\omega}_{t}$, so that the integrals in (14) have the same bounds. A sufficient condition for equation (15) to hold is that the integrand in the LHS exceed the integrand in the RHS for each $\omega$. It is verified that the required condition is

$$
\omega / 4 \geq \sqrt{k / 3} \quad, \quad \forall \omega \in\left[\hat{\omega}_{t}, \bar{\omega}\right]
$$

Because this condition is satisfied for the lower bound $\hat{\omega}_{t}=\sqrt{12 k}$, and the LHS in (16) is increasing in $\omega$, the condition is always satisfied.

Given the foregoing, Result 2 continues to hold when the mandate is calibrated so that the probability of $\mathrm{R} \& \mathrm{D}$ is lower than under a carbon tax. However, when mandates are chosen so that the probability of $\mathrm{R} \& \mathrm{D}$ is higher than under the carbon $\operatorname{tax} t=x$, then it is not apparent whether or not a mandate has lower expected welfare than a carbon tax. In such a case, the gain to welfare from inducing more innovation would need to be weighed against the costs of $\mathrm{R} \& \mathrm{D}$ and distortions to static welfare. We will return to this question in the numerical analysis of Section 6.

\section{Multiple innovators}

The preceding discussion pertains to the case of a single research firm. In reality, of course, many innovators are typically engaged in competing R\&D projects. To model this case, we postulate the existence of a large number of potential innovators, and we assume there is free entry into the renewable energy innovation sector. Innovators are ex ante identical and observe a common technological opportunity signal $\omega$. If they choose to conduct R\&D, they obtain independent $\theta$ 
draws from $f(\theta \mid \omega)$. The innovator who draws the highest $\theta$, denoted $\theta_{1}$, has the best technology and becomes the exclusive licensor to the renewable energy production sector. However, the choice of royalty by the innovator who draws $\theta_{1}$ is now constrained by the presence of competing innovators. Under Bertrand competition, the second-highest $\theta$ draw, denoted $\theta_{2}$, is the binding constraint. Essentially, as compared with the foregoing analysis, $\theta_{2}$ plays the same role as the preinnovation production technique $\theta=0$ for the single innovator case. But, of course, in the multiple innovator setting $\theta_{2}$ is endogenous.

To characterize the pricing of innovation with multiple innovators, consider first the laissez faire setting. The innovator with the expost best technology $\theta_{1}$, presuming that $\theta_{1}>\hat{\theta} \equiv c_{2}-c_{1}$, sets the per-unit license $r$ to maximize license profit, conditional on the competitive sector adoption, similar to the single-innovator setting. But here the second best technology $\theta_{2}$ may limit the price that the licensing innovator can extract. Specifically, the innovator with the best technology maximizes $r\left(c_{1}-c_{2}+\theta_{1}-r\right)$, such that $r \leq \theta_{1}-\theta_{2}$. For low realizations of $\theta_{2}$, the constraint imposed by the second-best technology does not bind, the single-innovator results continue to hold, and the solution is $r^{*}=Q_{2}=\left(\theta_{1}-\hat{\theta}\right) / 2$. Given this unconstrained royalty, it is apparent that the constraint $r \leq \theta_{1}-\theta_{2}$ binds whenever $\theta_{2}>\left(\theta_{1}+\hat{\theta}\right) / 2$. In such a case the optimal royalty is $r^{*}=\theta_{1}-\theta_{2}$, and $Q_{2}=\theta_{2}-\hat{\theta}$. The best innovator's maximum profit, denoted $\pi_{1}$, is therefore given by:

$$
\begin{array}{ll}
\pi_{1}=\frac{\left(\theta_{1}-\hat{\theta}\right)^{2}}{4} & \text { if } \theta_{2} \leq\left(\theta_{1}+\hat{\theta}\right) / 2 \\
\pi_{1}=\left(\theta_{1}-\theta_{2}\right)\left(\theta_{2}-\hat{\theta}\right) & \text { if } \theta_{2}>\left(\theta_{1}+\hat{\theta}\right) / 2
\end{array}
$$

The expected profit of a potential entrant now depends on the distribution of $\theta_{1}$ and $\theta_{2}$, which are best described by the concepts of "order statistics" widely used in auction theory (Krishna 2010). Specifically, given $n$ innovators, the probability that an innovator's draw of $\theta$ is the maximum draw is equal to the probability that the $n-1$ other draws are smaller than $\theta$. Because we have assumed a uniform distribution for the innovation projects, then

$$
\operatorname{Pr}\left(\theta=\theta_{1} \mid \omega, n\right)=(\theta / \omega)^{n-1}
$$


Moreover, conditional on a given $\theta$ being the maximum draw, the second highest realization $\theta_{2}$ is the maximum of $n-1$ independent draws from the uniform distribution on the support of $[0, \theta]$. This is described by the cumulative distribution function:

$$
\operatorname{Pr}\left(\theta_{2}<\theta \mid \omega, n\right)=\left(\theta_{2} / \theta\right)^{n-1}
$$

which implies that the density function of $\theta_{2}$ is $\left((n-1) / \theta_{2}\right)\left(\theta_{2} / \theta\right)^{n-1}$. Using these results on the distribution of the first and second best innovations, we can determine the expected profitability of participating in the R\&D contest. Specifically, with $n$ entrants, the expected profit of each innovator, given technological opportunity $\omega$, can be written as:

$$
\pi(\omega, n)=\int_{\hat{\theta}}^{\omega}\left\{\left(\frac{\theta+\hat{\theta}}{2 \theta}\right)^{n-1} \frac{(\theta-\hat{\theta})^{2}}{4}+\int_{(\theta+\hat{\theta}) / 2}^{\theta}\left(\theta-\theta_{2}\right)\left(\theta_{2}-\hat{\theta}\right) \frac{n-1}{\theta_{2}}\left(\frac{\theta_{2}}{\theta}\right)^{n-1} d \theta_{2}\right\}\left(\frac{\theta}{\omega}\right)^{n-1} \frac{1}{\omega} d \theta
$$

This term integrates over the range of values for $\theta$ that are both feasible and which earn positive profit. Within the integral, profits are divided into two terms. When $\theta_{2} \leq(\theta+\hat{\theta}) / 2$, which occurs with probability $[(\theta+\hat{\theta}) / 2 \theta]^{n-1}$, profit is given by equation (17). This is the first term under the integral. Conversely, whenever $\theta_{2}>\left(\theta_{1}+\hat{\theta}\right) / 2$, profit is given by equation (18). This is captured by the second term, itself an integral over possible values of $\theta_{2}$.

\subsection{Free Entry of Innovators Under a Carbon Tax}

With the naïve carbon tax $t=x$, the innovator's problem is similar in structure to the laissez faire setting. But here, if the pre-innovation technology is such that Condition 2 applies, it is as if $\hat{\theta}=0$. Hence, given $\theta_{1}$ and $\theta_{2}$, the best innovator's profit is:

$$
\pi_{t}= \begin{cases}\left(\theta_{1} / 2\right)^{2} & \text { if } \theta_{2} \leq \theta_{1} / 2 \\ \left(\theta_{1}-\theta_{2}\right) \theta_{2} & \text { if } \theta_{2}>\theta_{1} / 2\end{cases}
$$

Given this conditional profit function, equation (21) can be adapted to yield the expected profit $\pi_{t}(\omega, n)$ of each innovator facing technological opportunity $\omega$ when there are $n$ innovators engaged in R\&D: 


$$
\pi_{t}(\omega, n)=\int_{0}^{\omega}\left\{\left(\frac{1}{2}\right)^{n-1}\left(\frac{\theta_{1}}{2}\right)^{2}+\int_{\theta_{1} / 2}^{\theta_{1}} \frac{n-1}{\theta_{2}}\left(\frac{\theta_{2}}{\theta_{1}}\right)^{n-1}\left(\theta_{1}-\theta_{2}\right) \theta_{2} d \theta_{2}\right\}\left(\frac{\theta_{1}}{\omega}\right)^{n-1} \frac{1}{\omega} d \theta_{1}
$$

Performing the integration, and simplifying, yields:

$$
\pi_{t}(\omega, n)=\frac{n-\left(1-(1 / 2)^{n}\right)}{n(n+1)(n+2)} \omega^{2}
$$

Note that when $n=1$ equation (24) reduces to $\omega^{2} / 12$, which is what we found the single innovator profit to be in section 3.2. Profit is clearly increasing in technological opportunity $\omega$. It is also verified that profit is decreasing in the number of innovators $n$ (this occurs for two distinct reasons: as $n$ increases, the probability of any one participant drawing the highest innovations decreases; and, as $n$ increases, the expected royalty for any given innovation decreases).

The equilibrium number of innovators is determined by the free entry condition. In equilibrium, noting that $n$ is an integer, the number of innovators $n_{t}^{*}$ satisfies:

$$
\pi_{t}\left(\omega, n_{t}^{*}\right) \geq k \geq \pi_{t}\left(\omega, n_{t}^{*}+1\right)
$$

To emphasize the dependence of the equilibrium number of firms on the R\&D outlook parameter $\omega$, which represents the asymmetric information between innovators and policy makers, in what follows this is denoted $n_{t}^{*}=n_{t}(\omega)$.

In section 3.2 we found there existed a unique threshold $\hat{\omega}_{t}$, where R\&D occurred whenever $\omega \geq \hat{\omega}_{t}$. With free entry, an analogous result can be stated as follows.

Remark 3. Equilibrium with free R\&D entry and a carbon tax implies the existence of a sequence of thresholds $\hat{\omega}_{t}(n)$ such that there are at least $n$ active innovators iff $\omega \geq \hat{\omega}_{t}(n)$.

The threshold levels $\hat{\omega}_{t}(n)$ are readily computed from (24) and (25):

$$
\hat{\omega}_{t}(n)=\sqrt{\frac{n(n+1)(n+2)}{n-1+(1 / 2)^{n}} k}
$$


A corollary is that, under free entry, some $R \& D$ will take place whenever it is an equilibrium outcome to have at least one innovator, i.e., $\omega \geq \hat{\omega}_{t}(1)$, which occurs when $\omega \geq \sqrt{12 k}$. Naturally, this is the same condition as in the single-innovator case.

As in the single innovator case, consumer surplus is not impacted by innovation, since the price and quantity of final energy is unchanged. Hence, innovation only affects welfare through the profit accruing to the winning innovator and the producer surplus of clean producers-denoted $\pi_{t}^{*}\left(\omega, n_{t}(\omega)\right)$ and $\Pi_{t}\left(\omega, n_{t}(\omega)\right)$, respectively—and total R\&D costs $n_{t}(\omega) k$. Expected welfare can be expressed as:

$$
E[W]=S_{0}^{*}+\int_{0}^{\bar{\omega}}\left\{\pi_{t}^{*}\left(\omega, n_{t}(\omega)\right)+\Pi_{t}\left(\omega, n_{t}(\omega)\right)-n_{t}(\omega) k\right\} d G(\omega)
$$

\subsection{Free Entry of Innovators Under a Mandate}

Under a quota mandate, distributors must ensure $Q_{2} \geq \hat{Q}$. The problem faced by an innovator is the same as in section 2.3, but, because of the presumption of Bertrand competition, with the binding constraint now given by the second best technology, where $\theta_{2} \geq 0$. This constraint imposes more limitations on the choice of royalty. Specifically, Condition 4 invoked earlier for the single innovator case may no longer suffice to guarantee that the mandate binds. Instead, whenever

$$
c_{2}-\theta_{2}+\hat{Q}<c_{1}
$$

then the second-best technology is sufficiently good that clean firms would want to use it and exceed the mandate if this technology were competitively priced. The best technology, of course, pre-empts adoption of the second-best technology, but the winning innovator must choose the royalty rate as in the laissez-faire setting discussed earlier, in this case leading to an adoption level that exceeds the mandate. The best possible $\theta_{2}$ is $\bar{\omega}$ and so we assume:

Condition 5. The mandate is large enough to always bind, i.e., $\hat{Q} \geq \bar{\omega}-\left(c_{2}-c_{1}\right)$.

This condition is stronger than Condition 4. Note that the best possible $\theta_{1}$ is also $\bar{\omega}$ and so Condition 5 ensures that the winning innovator cannot choose a royalty such that the mandate is exceeded. 
If Condition 5 does not hold, then there will be cases where the winning innovator exceeds the mandate and competes with the fossil fuel alternative as in the laissez-faire case. The resulting profits, however, are lower than if fossil fuels were subjected to a carbon tax. Therefore, any draws of $\theta_{1}$ and $\theta_{2}$ that lead the winning firm to exceed $\hat{Q}$ are valued less under a mandate than they would be under a carbon tax, and this reduces the incentive to invest in $\mathrm{R} \& \mathrm{D}$ when such draws are possible. Hence, in the analytical derivations that follow we continue to assume that $\hat{Q}$ and $\bar{\omega}$ are such that the mandate is always binding in the post-innovation situation (which provide the best possible set of conditions for the effectiveness of a mandate vis-à-vis the carbon tax). We will return to the possibility that the mandate does not bind in the numerical simulations reported in Section 6.

Given a binding mandate, an innovating firm in possession of the best technology $\theta_{1}$ chooses the royalty rate to maximize $r \hat{Q}$, such that $c_{2}-\theta_{1}+\hat{Q}+r \leq c_{2}-\theta_{2}+\hat{Q}$. The latter indicates the constraint that marginal costs using the best technology, while paying a royalty $r$, must not exceed marginal costs using the second best technology with a royalty of zero. Clearly, the optimal royalty is $r^{*}=\theta_{1}-\theta_{2}$ and the quantity induced is $\hat{Q}$. Therefore, the profit of an innovator with the best technology $\theta_{1}$, facing the second best technology $\theta_{2}$, is:

$$
\pi_{m}=\left(\theta_{1}-\theta_{2}\right) \hat{Q}
$$

Using the probabilities given by equations (19) and (20), the expected profit of each entrant in the $\mathrm{R} \& \mathrm{D}$ contest, given $n$ innovators and technological opportunity $\omega$, is:

$$
\pi_{m}(\omega, n)=\int_{0}^{\omega}\left\{\int_{0}^{\theta_{1}} \frac{n-1}{\theta_{2}}\left(\frac{\theta_{2}}{\theta_{1}}\right)^{n-1}\left(\theta_{1}-\theta_{2}\right) \hat{Q} d \theta_{2}\right\}\left(\frac{\theta_{1}}{\omega}\right)^{n-1} \frac{1}{\omega} d \theta_{1}
$$

After integrating and simplifying, we obtain:

$$
\pi_{m}(\omega, n)=\frac{\hat{Q}}{n(n+1)} \omega
$$

Expected profit is increasing in technological opportunity $\omega$ and the mandate $\hat{Q}$, and decreasing in the number of innovators. The equilibrium number of innovators $n_{m}^{*}=n_{m}(\omega)$ satisfies: 


$$
\pi_{m}\left(\omega, n_{m}^{*}\right) \geq k \geq \pi_{m}\left(\omega, n_{m}^{*}+1\right)
$$

Remark 4. Equilibrium with free R\&D entry and a mandate policy implies the existence of a series of thresholds $\hat{\omega}_{m}(n)$ such that there are at least $n$ active innovators iff $\omega \geq \hat{\omega}_{m}(n)$.

These threshold levels $\hat{\omega}_{m}(n)$ are computed from (31) and (32):

$$
\hat{\omega}_{m}(n)=\frac{n(n+1)}{\hat{Q}} k
$$

Under free entry, there will be some R\&D whenever $\omega \geq \hat{\omega}_{m}(1)$, or $\omega \geq 2 k / \hat{Q}$. Naturally, this is the same condition found in section 3.3 for the single innovator case.

Expected welfare under a mandate is no longer straightforward in the presence of multiple innovators. A major difference is that, in the single innovator case, the innovating firm appropriated all of the gains from innovation, so that the price of clean fuel was unchanged by innovation. Under free entry, on the other hand, the winning innovator is only able to appropriate the gains to innovation stemming from improvements over the second best innovation. This also means that the price of clean fuel falls by $\theta_{2}$ which, because the price consumers pay for energy under a mandate is given by $\tilde{P}(Q)$ in equation (9), leads to an expansion of demand and to a new equilibrium $Q^{\prime}$ satisfying $\tilde{P}\left(Q^{\prime}\right)=P\left(Q^{\prime}\right)$, where $Q^{\prime}>Q^{0}$ and $Q^{0}$ is the pre-innovation equilibrium with mandates. Given a binding mandate, this demand expansion is met entirely by increased dirty fuel production. Whereas the price decline due to the innovation raises consumer surplus, it also increases damages from externalities by $\left(Q^{\prime}-Q^{0}\right) x$. The increase in damage from the externality exceeds the gain in consumer surplus whenever:

$$
\left(Q^{\prime}-Q^{0}\right) x>\int_{Q^{0}}^{Q^{\prime}} P(q) d q-P\left(Q^{\prime}\right) Q^{\prime}+P\left(Q^{0}\right) Q^{0}
$$

This condition can be rewritten as:

$$
\int_{Q^{0}}^{Q^{\prime}}\left[x-\left(P(q)-P\left(Q^{\prime}\right)\right)\right] d q>\left(P\left(Q^{0}\right)-P\left(Q^{\prime}\right)\right) Q^{0}
$$


The right side of equation (35) is always positive, and so this equation can never be satisfied when

$x<\left(P\left(Q^{0}\right)-P\left(Q^{\prime}\right)\right)$, i.e., when the change in price is greater than marginal damage. Equation (35) is

most likely to hold when demand is highly elastic, so that $Q^{\prime}$ is much larger than $Q^{0}$ but the change in price is small relative to marginal damage.

RESULT 3. Under a mandate, the positive welfare impact of innovation is reduced by an expansion of dirty energy consumption. This effect is more sizeable when demand is sufficiently elastic and marginal damage is sufficiently high.

This result establishes that innovation under a mandate is susceptible to a form of the so-called rebound effect. A mandate acts like a tax on the consumption of dirty energy because the use of expensive renewable energy raises the overall cost of energy. But as innovation reduces the cost of renewable energy, the cost of all energy also falls. The increase in total demand is then entirely met by dirty fuel when, as in the case being analyzed, the mandate remains binding.

Under free entry, consumer surplus, clean producer profits, and externalities all depend on the second-best technology, and through this channel their expected values depend on $\omega$. Overall welfare is now written as:

$$
E[W]=\int_{0}^{\bar{\omega}}\left\{E\left[S^{m} \mid \omega\right]+E\left[\Pi^{m} \mid \omega\right]-E\left[X^{m} \mid \omega\right]+\pi_{m}^{*}\left(\omega, n_{m}(\omega)\right)-n_{m}(\omega) k\right\} d G(\omega)
$$

\section{Mandate vs. Carbon Tax with Multiple Innovators}

With multiple innovators and free entry in the R\&D contest, the choice between a carbon tax and a mandate has a greater impact on the character of the realized innovation. To begin, it is more likely there will be at least $n$ innovators under a carbon tax than under a mandate whenever $\hat{\omega}_{m}(n) \geq \hat{\omega}_{t}(n)$. By using equations (26) and (33), and simplifying, this condition reduces to:

$$
\frac{k}{\hat{Q}^{2}} \geq \frac{n+2}{\left(n-1+(1 / 2)^{n}\right) n(n+1)}
$$

For any given policy the left hand side is fixed, while the right hand side is decreasing in $n$. This suggests there is a threshold $\hat{n}$ such that at least $n$ innovators are more likely under a carbon tax whenever $n>\hat{n}$, where $\hat{n}$ is defined by: 


$$
\frac{\hat{n}+1}{\left(\hat{n}-2+(1 / 2)^{\hat{n}-1}\right)(\hat{n}-1) \hat{n}} \geq \frac{k}{\hat{Q}^{2}} \geq \frac{\hat{n}+2}{\left(\hat{n}-1+(1 / 2)^{\hat{n}}\right) \hat{n}(\hat{n}+1)}
$$

Because $\hat{\omega}_{m}(n) \geq \hat{\omega}_{t}(n)$ for all $n \geq \hat{n}$, and given that $\hat{\omega}_{m}(n)$ and $\hat{\omega}_{t}(n)$ are monotonically increasing in $n$, we conclude with the following result.

RESULT 4. Whenever technological opportunity exceeds a threshold, i.e., $\omega \geq \hat{\omega}_{t}(\hat{n})$, the number of innovators is (weakly) higher under a carbon tax than under a mandate.

Conversely, whenever $\omega \leq \hat{\omega}_{t}(\hat{n})$, the number of innovators is (weakly) higher under a mandate policy than a carbon tax.

Under either policy, the realized innovation is the best technology drawn by any of the innovators, denoted $\theta_{1}$. Conditional on the technology opportunity parameter $\omega$ and the number of innovators $n$, the expected new technology is

$$
E\left[\theta_{1} \mid n, \omega\right]=\int_{0}^{\omega} \theta f_{1}(\theta \mid n, \omega) d \theta
$$

where $f_{1}(\theta \mid n, \omega)$ here is the density function of the distribution of the highest order statistics, which can be related to the primitive distribution $f(\theta \mid \omega)$ (Krishna 2010). Because of our assumed uniform distribution $f(\theta \mid \omega)=\theta / \omega$, it follows that

$$
f_{1}(\theta \mid n, \omega)=n\left(\frac{\theta}{\omega}\right)^{n-1} \frac{1}{\omega}
$$

Using this density function and performing the integration in (39) we find:

$$
E\left[\theta_{1} \mid n, \omega\right]=\frac{n}{n+1} \omega
$$

Of course, as discussed in the foregoing, the equilibrium number of innovators will depend on the actual technology opportunity $\omega$ and on the policy in place, i.e., $n=n_{i}(\omega), i=t, m$. Furthermore, from the perspective of a social planner (who does not observe $\omega$ ), what is relevant is the unconditional expectation of the best technology, that is 


$$
E\left[\theta_{1}\right]=\int_{0}^{\bar{\omega}} \frac{n_{i}(\omega)}{n_{i}(\omega)+1} \omega d G(\omega)
$$

This makes it apparent that, given the primitive distribution of technological opportunities $G(\omega)$, the expected technology realized depends only on the number of innovators induced by the policy $i=t, m$ for every opportunity $\omega$.

In section 2.4 we showed that, for the single innovator case, setting a mandate equal to $\hat{Q}=\sqrt{k / 3}$ ensures that R\&D occurs under either policy with equal probability. Using the same policy under free entry preserves this property, but Result 2-according to which the expected technology in use is the same under either policy-is no longer true. When $\hat{Q}=\sqrt{k / 3}$, then equation (38) is satisfied by $\hat{n}=1$ and $n_{t}(\omega) \geq n_{m}(\omega)$ for all $\omega$. By equation (42) this implies the expected technology in use will be higher under a carbon tax.

RESULT 5. When the mandate is tuned so that the probability of R\&D under a mandate is equal to the probability of R\&D under a carbon tax, then the expected technology realized after innovation is better under a carbon tax.

What if the mandate $\hat{Q}$ were tuned so that the expected best technology is the same as under the carbon tax? In order for $E\left[\theta_{1}\right]$ to be the same under either policy, the mandate must be increased from $\sqrt{k / 3}$, so that $\hat{\omega}_{m}(n)$ is decreased. Because $\hat{\omega}_{m}(n)=n(n+1) k / \hat{Q}$, increasing $\hat{Q}$ will decrease $\hat{\omega}_{m}(n)$ for all $n$. Specifically, we will now have $\hat{\omega}_{m}(1)<\hat{\omega}_{t}(1)$ so that $\mathrm{R} \& \mathrm{D}$ is more likely to occur under a mandate than under a carbon tax. Moreover, for $E\left[\theta_{1}\right]$ to be the same under either policy, it cannot be that $n_{m}(\bar{\omega})>n_{t}(\bar{\omega})$, where $n_{i}(\bar{\omega})$ is the number of innovators under policy $i$ and the best possible technological opportunity. If this were the case, then by Result $4, n_{m}(\omega)>n_{t}(\omega)$ for all $\omega \in[0, \bar{\omega}]$ and by equation (42) $E\left[\theta_{1}\right]$ would be higher under a mandate. Therefore, in this setting, there is some intermediate threshold $\hat{n}$, satisfying $1<\hat{n}<n_{m}(\bar{\omega})$, where the number of innovators is higher under a carbon tax for $\omega \geq \hat{\omega}_{t}(\hat{n})$ and higher under a mandate otherwise. This implies: 
RESULT 6. When the mandate is tuned so that the expected best technology is the same under either policy, then the distribution of outcomes under a carbon tax is more disperse than under a mandate.

This result asserts that under a carbon tax there is a higher probability of a very good innovation or none at all. A mandate has a higher probability of some innovation, but a lower probability of a very good innovation, since it produces weaker incentives to innovate when technological opportunity is very high.

\section{Numerical Analysis}

The foregoing analysis has provided some interesting qualitative results on the comparison between mandates, laissez-faire and a carbon tax. While these results are illuminating, a limitation is that, apart from Result 2, not much has been said about welfare effects. This is not surprising: as equation (36) indicates, specific welfare conclusions should depend on the particular shape of the demand function $P(Q)$ and on the distribution of technological opportunities $G(\omega)$. Also, our analytical results have been contingent on a few assumptions: that clean energy cannot capture the entire market (Condition 1), that it is on the cusp of being competitive with (taxed) fossil fuels (Condition 2), and that the mandate is always binding (Conditions 4 and 5). In this section we relax these conditions and specify explicit functional forms for $P(Q)$ and $G(\omega)$ so that we may consider welfare effects by means of a numerical analysis.

\subsection{Parameterization}

We begin by normalizing $c_{1}=100$, so that a tax on dirty energy can be interpreted as a percent of the laissez-faire price level. In the baseline parameterization the externality is calibrated to $x=20$, so that it amounts to $20 \%$ of the private cost of dirty energy, ${ }^{5}$ and we put $c_{2}=120$, consistent with

\footnotetext{
${ }^{5}$ This value for the externality cost is meant to be somewhat representative of estimates for the social cost of carbon relative to the cost of transportation fuel. The US government's estimate for the 2015 social cost of carbon, in 2007 dollars, is $\$ 37 /$ ton of CO2 if a 3\% discount rate is used, and $\$ 57 /$ ton of CO2 if a $2.5 \%$ discount rate is used (US Government 2013, p. 3). These discount rates have been criticized for being too high (Johnson and Hope 2012), and so we use the figure associated with the lower $2.5 \%$ discount rate as our baseline. Converting this estimate to 2015 dollars yields a social cost of $\$ 65 /$ ton of CO2. The carbon emission coefficient is $8.9 \mathrm{~kg} \mathrm{CO} 2 / \mathrm{gallon}$ of gasoline (EPA 2014), which implies a social cost of carbon is $\$ 0.58$ per gallon. Taking the
} 
Condition 2 (but this condition does not hold when the marginal damage $x$ is changed from its baseline value). Next, we postulate the inverse demand function $p(Q)=(a-\ln Q) / b$ or, equivalently, that the direct demand function for energy takes the semi-log form:

$$
\ln Q=a-b p
$$

This is a convenient parameterization which, among other desirable features, can accommodate various hypotheses concerning demand elasticity $\eta \equiv-\partial \ln Q / \partial \ln p$. For or this function $\eta=b p$, hence the parameter $b$ can be varied to implement alternative elasticity values. The parameter $a$ is calibrated so that total demand for energy at price $p=c_{1}$ (and at the baseline elasticity value) is equal to $Q=100$, that is we put $a=b c_{1}+\ln 100$. This normalization means that we can interpret the level of mandates as the percent of total demand under a laissez-faire policy. As for $G(\omega)$, we assume that $\omega$ is distributed on $[0, \bar{\omega}]$ by an appropriately scaled beta distribution. The probability density function $g(\omega)$ is therefore given by:

$$
g(\omega ; \alpha, \beta) \propto(\omega / \bar{\omega})^{\alpha-1}(1-\omega / \bar{\omega})^{\beta-1}
$$

where the parameters $\alpha$ and $\beta$ determine the moments of this distribution and govern its shape. This distribution is very flexible, and alternative choices of $\alpha$ and $\beta$ can yield both symmetric and skewed density functions. We normalize $\bar{\omega}=120$ so that, under all possible innovation, the marginal cost of clean energy remains non-negative everywhere.

Given the foregoing functional form assumptions and parametric normalizations, we still have four free parameters that can be varied to gain some insights in the nature of the results. The first of these is the elasticity of demand $\eta$. Because this value depends on the evaluation price, for clarity we will always measure elasticity with reference to the laissez-faire price of energy, where $p=c_{1}$. For our baseline, we set $b$ so that $\eta=0.5$. We also consider the cases where $\eta=0.25$ and $\eta=1$. Second, we vary the cost of the externality $x$. As noted, for the baseline we set $x=20$, but we also consider the cases of $x=10$ and $x=40$. Third, we vary the $\mathrm{R} \& \mathrm{D}$ cost $k$. To calibrate this parameter we relate it to the magnitude of profits that innovation can produce in the laissez-faire baseline. Under the highest

benchmark price of gasoline to be $\$ 3.00 /$ gallon, then the damage imposed by the carbon externality is approximately $20 \%$ of the cost of fuel, which is reflected in our baseline value of . $x=20$. 
level of technological opportunity, the expected profit for a single innovator, in view of (5) and the chosen normalizations, is equal to $\pi_{t}(\bar{\omega})=6,250 / 9$. We consider values of $k$ equal to $3 \%, 6 \%$, and $12 \%$ of this profit level, with $6 \%$ corresponding to the baseline.

Fourth, we vary the shape of the distribution of technological opportunity $G(\omega)$. The first moment of the assumed beta distribution is $E[\omega]=\bar{\omega} \alpha /(\alpha+\beta)$. We set $\alpha+\beta=2$ and, by varying the parameters $\alpha$ and $\beta$, we obtain both different values for $E[\omega]$ and different shapes. The baseline parameters are $\alpha=0.5$ and $\beta=1.5$, which yield $E[\omega]=30$. This is a positively skewed distribution (low draws of $\omega$ are more likely than high ones), which reflects the belief that incremental innovation is generally more likely than major breakthroughs. The other two cases we consider are $\alpha=0.25$ and $\beta=1.75$, which yield $E[\omega]=15$ (and correspond to an even more positively skewed distribution), and $\alpha=1$ and $\beta=1$, which yield $E[\omega]=60$ (and correspond to a uniform distribution where high draws of $\omega$ are equally likely as low ones).

As for the policies $t$ and $\hat{Q}$, for each set of parameters that we consider, we numerically solve for the value of the policy instrument that maximizes welfare (expected Marshallian surplus).

\subsection{Results}

The experiments we report, as described in the foregoing, encompass $3^{4}=81$ different parameter combinations. All calculation are coded in Matlab. Some basic descriptive results for the baseline parameters are reported in Table 1. For the single innovator case the expected number of innovators $E[n]$ can be interpreted as the probability that $\mathrm{R} \& \mathrm{D}$ will be conducted. In the baseline setting, under a laissez-faire policy, R\&D is conducted with probability 0.25 for the single innovator case. The expected quality of innovation $E\left[\theta_{1}\right]$ is 9.66 , which improves to 16.05 with multiple innovators. Hence, in either case the "average" technology under laissez faire is insufficient to compete with fossil fuels (the minimum inventive step here is $\hat{\theta}=20$ ). Still, some innovation does take place under laissez-faire, because some better-than-average draws are viable. The expected quantity of clean energy consumed is small but not negligible, at 2.64 and 8.94 under the single innovator and free entry conditions respectively (recall that the laissez-faire quantity of total energy consumed was normalized to 100). 
Table 1. Numerical Results for Baseline

\begin{tabular}{|l|r|r|r|r|r|r|}
\hline & \multicolumn{2}{|c|}{ Laissez-Faire } & \multicolumn{2}{c|}{ Mandate } & \multicolumn{2}{c|}{ Carbon Tax } \\
\hline & $\begin{array}{c}\text { Single } \\
\text { Innovator }\end{array}$ & $\begin{array}{c}\text { Free } \\
\text { Entry }\end{array}$ & $\begin{array}{c}\text { Single } \\
\text { Innovator }\end{array}$ & $\begin{array}{c}\text { Free } \\
\text { Entry }\end{array}$ & $\begin{array}{c}\text { Single } \\
\text { Innovator }\end{array}$ & $\begin{array}{c}\text { Free } \\
\text { Entry }\end{array}$ \\
\hline $\begin{array}{l}\text { Optimal } \\
\text { instrument }\end{array}$ & - & - & 18.65 & 16.05 & 23.45 & 23.40 \\
\hline$E[n]$ & 0.25 & 1.52 & 0.78 & 2.66 & 0.56 & 3.08 \\
\hline$\sqrt{\operatorname{Var}(n)}$ & 0.44 & 3.10 & 0.42 & 2.83 & 0.50 & 3.95 \\
\hline$E\left[\theta_{1}\right]$ & 9.66 & 16.05 & 15.63 & 24.76 & 14.44 & 24.17 \\
\hline$\sqrt{\operatorname{Var}\left(\theta_{1}\right)}$ & 20.59 & 30.15 & 19.8 & 28.16 & 20.45 & 29.95 \\
\hline$E\left[Q_{2}\right]$ & 2.64 & 8.94 & 18.66 & 21.68 & 9.76 & 23.32 \\
\hline$\sqrt{\operatorname{Var}\left(Q_{2}\right)}$ & 6.99 & 19.31 & 0.56 & 14 & 9.68 & 26.98 \\
\hline$E[W]$ & 126 & 412 & 146 & 455 & 315 & 689 \\
\hline$\sqrt{\operatorname{Var}(W)}$ & 421 & 997 & 369 & 993 & 544 & 1,114 \\
\hline
\end{tabular}

Note: the baseline parameters are $\eta=0.5, x=0.2 c_{1}, k=0.06 \pi(\bar{\omega})$, and $\alpha=0.5$ and $\beta=1.5$ (i.e., $E[\omega]=30)$.

An optimal policy (either a mandate or a tax) raises all these quantities, and also improves welfare.

The expected quality of innovation $E\left[\theta_{1}\right]$ is also increased significantly, as well as the quantity of clean energy produced. Under an optimal mandate, the probability of R\&D more than triples, relative to the laissez-faire case, and the expected number of innovators, given free entry, increases from 1.52 to 2.66. Compared with the carbon tax, the mandate induces a greater probability of innovation with a single innovator, but a carbon tax has a higher expected number of entrants when there is free entry. As discussed earlier, this is because a mandate provides comparatively strong incentives to conduct $\mathrm{R} \& \mathrm{D}$ when technological opportunity is low, and this induces firms to enter for more draws of $\omega$ than under a carbon tax. The expected profit of R\&D increases as $\omega$ rises, but it increases at a faster rate for the carbon tax. In the single innovator case, this is irrelevant, since firms make a binary decision to conduct $\mathrm{R} \& \mathrm{D}$ or not. But in the free entry case, the higher profits of a carbon tax can support more innovators, and this leads to a higher overall expected number of entrants (3.08 in a carbon tax, compared to 2.66 under a mandate). The expected quality of innovation, however, is actually higher under a mandate in each case. In the free entry case, this stems from the differential impact of entrants. Consistent with Result 6 , we note that carbon taxes will tend to have more disperse results than the mandate, inducing either many innovators or none 
at all. Because $\partial E\left[\theta_{1} \mid \omega, n\right] / \partial n$ is decreasing in $n$, the marginal impact of additional entrants under a tax when $\omega$ is high (and there are already many firms) is lower than that of additional entrants under a mandate when $\omega$ is low (and there are few or no entrants).

The expected quantity of clean energy produced is higher under a mandate, when there is a single innovator, but higher under a carbon tax in the free entry case. However, in both single and multiple innovators cases, welfare is higher under an optimal carbon tax. ${ }^{6}$ In fact, this is a general numerical result, and we have found it to be true beyond the baseline.

RESULT 7 (NUMERICAL). In all parametric combinations that we considered, expected welfare under the optimal mandate is always lower than under the optimal carbon tax.

Result 7 refers to 81 different parameter combinations, each of which is solved under single innovator and free entry conditions. This result suggests that an optimal mandate, while it improves welfare relative to laissez-faire, is inferior to an optimal carbon tax.

To gain further insights into the performance of an optimal mandate, relative to both laissez-faire and a carbon tax, Table 2 illustrates the sensitivity of optimal policies to changes in the calibrated parameters. The first row of Table 2 reiterates the optimal policies for the baseline parameterization reported in Table 1. Each subsequent row presumes the same parameters as the baseline, except along one dimension. For example, in the second row the elasticity of demand, evaluated at the laissez-faire price, is changed to $\eta=0.25$. It is apparent that, across columns, the optimal mandate is considerably more variable that the optimal carbon tax. This suggests the optimal choice of a mandate is sensitive to information about the innovation context, about which policy makers might be less informed than innovators. This conclusion is buttressed by the last two lines of Table 2, which give the optimal policies when the outlook for technological innovation is altered. If this outlook improves from $E[\omega]=30$ to $E[\omega]=60$, the optimal mandate increases by $69 \%$ in the single innovator case and $108 \%$ in the free entry case, whereas the optimal carbon tax increases by $25 \%$ and $6 \%$, respectively. There is a similarly large divergence when technological opportunity decreases to $E[\omega]=15$.

\footnotetext{
${ }^{6}$ Throughout, welfare is measure as expected Marshallian surplus, normalized to zero at the preinnovation, laissez-faire case.
} 
Table 2. Optimal Policy Instruments Under Alternative Assumptions

\begin{tabular}{|l|r|r|r|r|r|r|}
\hline & \multicolumn{4}{|c|}{ Optimal Mandate } & \multicolumn{3}{c|}{ Optimal Carbon Tax } \\
\hline & $\begin{array}{c}\text { No } \\
\text { Innovation }\end{array}$ & $\begin{array}{c}\text { Single } \\
\text { Innovator }\end{array}$ & $\begin{array}{c}\text { Free } \\
\text { Entry }\end{array}$ & $\begin{array}{c}\text { No } \\
\text { Innovation }\end{array}$ & $\begin{array}{c}\text { Single } \\
\text { Innovator }\end{array}$ & $\begin{array}{c}\text { Free } \\
\text { Entry }\end{array}$ \\
\hline Baseline & 2.4 & 18.6 & 16.0 & 20.0 & 23.5 & 23.4 \\
\hline$\eta=0.25$ & 1.1 & 1.5 & 13.3 & 20.0 & 24.4 & 23.4 \\
\hline$\eta=1$ & 5.2 & 15.2 & 16.0 & 20.0 & 22.5 & 22.7 \\
\hline$x=10$ & $0.0^{*}$ & $0.0^{*}$ & $0.0 *$ & 10.0 & 14.0 & 14.4 \\
\hline$x=40$ & 30.3 & 41.8 & 47.0 & 40.0 & 47.8 & 42.8 \\
\hline$k=0.03 \bar{\pi}$ & 2.4 & 18.6 & 16.6 & 20.0 & 23.9 & 22.3 \\
\hline$k=0.12 \bar{\pi}$ & 2.4 & 18.1 & 16.0 & 20.0 & 23.0 & 24.0 \\
\hline$E[\omega]=15$ & 2.4 & 9.5 & 10.0 & 20.0 & 21.7 & 21.8 \\
\hline$E[\omega]=60$ & 2.4 & 31.4 & 33.3 & 20.0 & 29.3 & 24.8 \\
\hline
\end{tabular}

Note: Each row changes one parameter, all other parameters as in the baseline.

* reflects rounding (optimal mandates are strictly positive)

In view of the fact, illustrated in Table 2 , that the optimal carbon tax is less sensitive to the innovation context than the optimal mandate, we also compared the performance of the naive carbon $\operatorname{tax} t=x$ (which, strictly speaking, is optimal only without the prospect of innovation) with the optimal mandate. This comparison is of some interest, in an applied policy context, because the information requirement to compute this tax level is clearly much lower than required by the optimal instruments. It turns out that, for the multiple-innovators case, even the naïve carbon tax dominates the optimal mandate in terms of welfare. ${ }^{7}$

RESULT 8 (NUMERICAL). When the number of innovators is endogenous, for all parametric combinations that we considered, expected welfare under the optimal mandate is always lower than under the naïve carbon tax.

Whereas Table 2 illustrates that the magnitude of an optimal policy is more sensitive to information about innovation under a mandate than under a carbon tax, Table 3 illustrates that welfare outcomes are also more sensitive. In this table we decompose the total welfare change $W_{1}^{*}-W_{0}^{0}$, where $W_{1}^{*}$

\footnotetext{
${ }^{7}$ In the single-innovator case, expected welfare was higher with the optimal mandate than with the naive carbon tax for 3 of the 81 parameters combinations that we considered.
} 
is the expected welfare with innovation under the optimal instrument choice (either mandate or carbon tax, all for the multiple-innovators case), and $W_{0}^{0}$ is welfare under laissez-faire and no innovation. The decomposition identifies the following four components:

$W_{1}^{0}-W_{0}^{0}:$ The gain in expected welfare due to innovation under laissez-faire;

$W_{0}^{n}-W_{0}^{0}:$ The "static" gain in expected welfare with a "naïve" level of the policy instrument (i.e., one that does not account for the prospect of innovation);

$\left(W_{1}^{n}-W_{0}^{n}\right)-\left(W_{1}^{0}-W_{0}^{0}\right): \quad$ The additional gain in expected welfare, relative to laissez-faire, due to policy-supported innovation (with a naïve level of the instrument);

$W_{1}^{*}-W_{1}^{n}:$ The additional gain in expected welfare from moving to an optimal level of the policy instrument.

Table 3. Welfare Decomposition under Alternative Assumptions (Free Entry)

\begin{tabular}{|c|c|c|c|c|c|c|}
\hline & & \multicolumn{4}{|c|}{ Decomposition } & \multirow{2}{*}{$\begin{array}{l}\text { Total } \\
\qquad W_{1}^{*}-W_{0}^{0}\end{array}$} \\
\hline & Policy & $W_{1}^{0}-W_{0}^{0}$ & $W_{0}^{n}-W_{0}^{0}$ & $\begin{array}{l}\left(W_{1}^{n}-W_{0}^{n}\right) \\
-\left(W_{1}^{0}-W_{0}^{0}\right)\end{array}$ & $W_{1}^{*}-W_{1}^{n}$ & \\
\hline \multirow{2}{*}{ Baseline } & Mandate & 412 & 2 & 3 & 37 & 455 \\
\hline & Tax & 412 & 97 & 173 & 7 & 689 \\
\hline \multirow{2}{*}{$\eta=0.25$} & Mandate & 412 & 1 & 2 & 25 & 440 \\
\hline & $\operatorname{Tax}$ & 412 & 49 & 173 & 8 & 643 \\
\hline \multirow{2}{*}{$\eta=1$} & Mandate & 347 & 11 & 15 & 35 & 408 \\
\hline & $\operatorname{Tax}$ & 347 & 76 & 98 & 5 & 526 \\
\hline \multirow{2}{*}{$x=10$} & Mandate & 323 & 0 & 0 & 0 & 323 \\
\hline & Tax & 323 & 25 & 56 & 9 & 412 \\
\hline \multirow{2}{*}{$x=40$} & Mandate & 591 & 400 & 178 & 128 & 1,297 \\
\hline & Tax & 591 & 575 & 497 & 7 & 1,670 \\
\hline \multirow{2}{*}{$k=0.03 \bar{\pi}$} & Mandate & 517 & 2 & 5 & 39 & 564 \\
\hline & Tax & 517 & 97 & 166 & 4 & 784 \\
\hline \multirow{2}{*}{$k=0.12 \bar{\pi}$} & Mandate & 288 & 2 & 4 & 28 & 322 \\
\hline & Tax & 288 & 97 & 172 & 9 & 567 \\
\hline \multirow{2}{*}{$E[\omega]=15$} & Mandate & 179 & 2 & 2 & 13 & 196 \\
\hline & Tax & 179 & 97 & 99 & 3 & 377 \\
\hline \multirow{2}{*}{$E[\omega]=60$} & Mandate & 1,364 & 2 & 3 & 103 & 1,473 \\
\hline & Tax & 1,364 & 97 & 317 & 14 & 1,791 \\
\hline
\end{tabular}


The largest component of the decomposition is the first column, which gives the gain in expected welfare from innovation in a laissez-faire setting. This feature is of some interest per se, as it emphasizes that the market mechanisms that rationalize the use of policy instruments to spur innovation also work, to a degree, when no such support is present. Under both policies being considered, the gains from policy-supported innovation, $\left(W_{1}^{n}-W_{0}^{n}\right)-\left(W_{1}^{0}-W_{0}^{0}\right)$, are generally as large or larger than the gains due to the static increase in allocative efficiency, $W_{0}^{n}-W_{0}^{0}$. The last column of the decomposition also has direct policy relevance, as it shows how much is gained from moving to an optimal policy that explicitly accounts for the prospect of innovation. This column indicates that the additional gain in welfare from moving to an optimal policy is small under a carbon tax. In the baseline, welfare rises by 97 from the increase in allocative efficiency, by 173 from additional innovation, but only by 7 when moving from the naïve carbon tax of 20 to the optimal carbon tax of 23.4. By contrast, under a mandate, the majority of the gain in welfare stems from moving from the no-innovation policy of 2.4 to the optimal policy of 16.0. A similar result obtains for each of our 9 scenarios: under a mandate, it really is important to tune the policy instrument in response to innovation, whereas with a carbon tax most of the welfare gain can be achieved with the naïve level of the policy instrument.

\section{Conclusion}

The direct impact of most environmental policy tools, such as carbon taxes and pollution permits, is to promote the internalization of the external costs of pollution: the reduction of social cost of pollution is achieved by increasing the private cost of (some) agents. It has long been recognized that the privatization of these costs, in addition to ameliorating the externality effect from a static perspective, also has an important dynamic implications because it creates R\&D incentives via the so-called induced innovation hypothesis. In this paper we have applied this perspective to the analysis of "mandates," a policy tool that is becoming increasing popular in renewable energy contexts.

We find that mandates can in fact improve upon laissez faire, and that the prospect of innovation increases the optimal mandate level. The innovation effects are critical and account for most of the desirable welfare impacts of this policy tool. Our numerical results, however, indicate that an optimally calibrated mandate may be much more sensitive to assumptions about innovation, such as the number of potential innovators and the outlook for technological opportunity, than 
characteristics of demand and the size of the externality. In general, the more promising is innovation, the higher the mandate ought to be. Indeed, the optimal mandate is such that it would typically induce welfare losses in the status quo without innovation. In any event, we find that the optimal mandate policy, although it is better than laissez faire, is clearly dominated by a carbon tax policy.

A novel contribution of our paper, stemming from the explicit stochastic innovation framework that we have developed, is to shed some light on the extent to which alternative policies matter for the distribution of the quality of innovation. In our setting, whereas policies are set based on the entire distribution of possible R\&D outlooks, innovators observe a signal on the actual innovation prospects before making their R\&D investment. Compared with a mandate, a carbon tax tends to create high profit opportunities when the outlook for R\&D turns out to be very good, which induces a flurry of activity that makes the realization of the good innovation outcome likely. Conversely, when the outlook for R\&D is weak, mandates may provide more incentive for innovation. Hence, mandates may be a useful policy tool to incentivize R\&D when only minor innovations are attainable (or, as for the case of corn-based ethanol mentioned in the introduction, when one deals with a mature technology so that the problem at hand is to promote adoption of existing technologies). But when the goal is to promote breakthrough innovations, as for the cited example of advanced biofuels, it seems that a carbon tax is preferable to mandates. We note that our qualitative conclusions appear consistent with an emerging empirical literature in renewable energy which shows that quantity-based policies have positive and statistically significant predictors of innovation only for older technologies, whereas price-based policies have positive and statistically significant impact for younger technologies (Johnstone, Hascic and Popp 2010).

Whereas mandates may be less effective at spurring innovation for breakthrough technologies, their superior ability to induce innovation when incremental innovation is more likely may make them desirable in some settings. For example, if learning-by-doing is believed to be an important source of technological advance in a field, then it may be more desirable to guarantee that there is some kind of innovation, even if it is of low quality, so that the dynamics of learning-by-doing can get started. Alternatively, when innovation proceeds in many incremental steps, mandates may provide higher incentives than a carbon tax for each step in isolation. Whether this translates into a better policy to promote innovation, however, further depends on the extent to which the patent system allows early 
innovators to capture a sufficient share of the profits from follow-on ideas, a somewhat distinct and complex issue in the economics of intellectual property rights (see, e.g., Scotchmer, 2004, chapter 5).

These caveats notwithstanding, our results indicate that, as a policy to promote environmental innovation, mandates have real limitations. Mandates provide strong incentives for low-quality innovation, but often these are not particularly desirable. Our numerical results further substantiate that welfare with an optimal mandate policy is always lower than with an optimal carbon tax. Indeed, even a naïve carbon tax that is not optimized to account for the prospect of innovation typically outperforms an optimal mandate. 


\section{References}

Acemoglu, D., P. Aghion, L. Bursztyn, and R.N. Stavins. "The Environment and Directed Technical Change.” American Economic Review 102(1), 2012: 131-66.

Barrett, S. "The coming global climate-technology revolution." The Journal of Economic Perspectives 23(2)(2009): 53-75.

Biglaiser, G. and J.K. Horowitz. "Pollution Regulation and Incentives for Pollution-Control Research.” Journal of Economics \& Management Strategy 3.4 (1994): 663-684.

Clancy, M. and G. Moschini. "Incentives for Innovation: Patents, Prizes, and Research Contracts." Applied Economic Perspectives and Policy 35(2)(2013): 206-241.

de Gorter, H. and D.R. Just. "The Economics of a Blend Mandate for Biofuels." American Journal of Agricultural Economics, 91(3), 2009: 738-750.

Delmas, M.A. and M.J. Montes-Sancho. "US state policies for renewable energy: Context and effectiveness." Energy Policy 39(5)(2011): 2273-2288.

Denicolo, V. "Pollution-reducing innovations under taxes or permits." Oxford Economic Papers 51(1), 1999, 184-199.

EPA. "EPA Proposes 2014 Renewable Fuel Standards, 2015 Biomass-Based Diesal Volume.” Regulatory Announcement. U.S. Environmental Protection Agency, EPA-420-F-13-048, November 2013.

EPA. "Greenhouse Gas Emissions from a Typical Passenger Vehicle.” Questions and Answers. U.S. Environmental Protection Agency, EPA-410-F-14-040a, May 2014.

Fischer, C., I.W.H. Parry, and W.A. Pizer. "Instrument choice for environmental protection when technological innovation is endogenous." Journal of Environmental Economics and Management 45.3 (2003): 523-545.

Haas, R., G. Resch, C. Panzer, S. Busch, M. Ragwitz, and A. Held. "Efficiency and effectiveness of promotion systems for electricity generation from renewable energy sources-Lessons from EU countries.” Energy 36(4)(2011): 2186-2193. 
Holland, S.P. "Emissions taxes versus intensity standards: Second-best environmental policies with incomplete regulation.” Journal of Environmental Economics and Management 63(3)(2012): 375-387.

Jaffe, A.B., R.G. Newell and R.N. Stavins. "Technological change and the environment." Chapter 11 in: K-G. Mäler and J.R. Vincent, eds. Handbook of Environmental Economics. Vol. 1, Elsevier Science, Amsterdam, pp. 461-516.

Jaffe, A.B., R.G. Newell and R.N. Stavins. "A Tale of Two Market Failures: Technology and Environmental Policy.” Ecological Economics 54, 2005: 164-174.

Janda, K., L. Kristoufek and D. Zilberman. "Biofuels: Policies and Impacts.” Agricultural Economics, 58(8)(2012): 372-386.

Johnson, Laurie T., and Chris Hope. "The social cost of carbon in U.S. regulatory impact analyses: an introduction and critique." Journal of Environmental Studies and Science 2(3) (2012): 205-221.

Johnstone, Nick, Ivan Hascic, and David Popp. "Renewable Energy Policies and Technological Innovation: Evidence Based on Citation Counts." Environmental Resource Economics 45, 2010: 133-155.

Khishna, V. Auction Theory, $2^{\text {nd }}$ edition. Amsterdam: Elsevier, 2010.

Kennedy, P.W. and B. Laplante. "Environmental policy and time consistency: emissions taxes and emissions trading." In: E. Petrakis, E.S. Sartzetakis and A. Xepapadeas, eds. Environmental Regulation and Market Power: Competition, Time Consistency and International Trade. Edward Elgar Pub, 1999.

Kydland, F. E. and E.C. Prescott. "Rules rather than discretion: The inconsistency of optimal plans." Journal of Political Economy 85(3) (1977): 473-491.

Laffont, J-J. and J. Tirole. "Pollution permits and environmental innovation." Journal of Public Economics 62(1), 1996, 127-140.

Lapan, H. and G. Moschini. "Second-Best Biofuel Policies and the Welfare Effects of Quantity Mandates and Subsidies." Journal of Environmental Economics and Management 63, 2012: 224-241. 
Moschini, G., Cui, J., and Lapan, H. "Economics of Biofuels: An Overview of Policies, Impacts and Prospects," Bio-based and Applied Economics, 1(3)(2012): 269-296.

Parry, I.W.H. “Optimal Pollution Taxes and Endogenous Technical Progress.” Resource and Energy Economics 17, 1995: 69-85.

Popp, D. "Innovation and climate policy." Annual Review of Resource Economics, 2 (1)(2010), 275-298.

Popp, D., R.G. Newell and A. Jaffe. "Energy, the environment, and technological change." Chapter 21 in: Hall, B. and N. Rosenberg (Eds.), Handbook of the Economics of Innovation, vol. 2 (pp. 873937). Elsevier, Amsterdam, 2010.

Requate, T. "Dynamic Incentives by Environmental Policy Instruments - A Survey.” Ecological Economics, 2005: 175-195,

Schnepf, R., and B.D. Yacobucci, "Renewable Fuel Standard (RFS): Overview and Issues," CRS Report for Congress 7-5700, Congressional Research Service: Washington, D.C., March 2013.

Scotchmer, S. Innovation and Incentives. Cambridge, MA: MIT Press, 2004.

Scotchmer, S. "Cap-and-trade, emissions taxes, and innovation.” In: J. Lerner and S. Stern, eds., Innovation Policy and the Economy, Volume 11, pp. 29-53. University of Chicago Press, 2011.

US Government. "Technical Support Document: - Technical Update of the Social Cost of Carbon for Regulatory Impact Analysis.” Executive Order 12866, Interagency Working Group on Social Cost of Carbon, May 2013, Revised November 2013. 